\title{
HUBUNGAN PENDIDIKAN STATUS KEPEGAWAIAN DAN LAMA KERJA DENGAN KINERJA PERAWAT MELAKSANAKAN ASUHAN KEPERAWATAN
}

\author{
THE RELATIONSHIP BETWEEN EDUCATION EMPLOYMENT STATUS AND \\ LENGTH OF WORK WITH THE PERFORMANCE OF NURSES IN IMPLEMENTING \\ NURSING CARE
}

\author{
Meistvin Welembuntu, Iswanto Gobel \\ Program Studi Keperawatan, Jurusan Kesehatan,Politeknik Negeri Nusa Utara \\ Email: meistvin@yahoo.com
}

\begin{abstract}
Abstrak: Pelayanan keperawatan merupakan salah satu ujung tombak pelayanan kesehatan yang sangat penting di masyarakat/puskesmas, pelayanan tersebut berfokus pada penerapan asuhan keperawatan yang berkualitas dimana hal itu dapat tercapai bila diberikan oleh perawat profesional yang memiliki motivasi serta berkinerja tinggi. Kemampuan tersebut dapat dipengaruhi oleh berbagai faktor yang bisa bersumber dari diri perawat itu sendiri maupun faktor eksternal lainnya, oleh karena itu pihak manajemen harus mampu mengidentifikasi hal diatas sehingga dapat memberikan solusi guna tercapainya penerapan asuhan keperawatan yang bermutu. Tujuan penelitian untuk melihat hubungan antara karakteristik responden dengan kinerja perawat dalam melaksanakan asuhan keperawatan di Puskesmas rawat inap Kabupaten Kepulauan Sangihe. Metode yang digunakan yakni cross sectional melihat hubungan antara pendidikan, status kepegawaian dan lama kerja dengan kinerja perawat dalam melaksanakan asuhan keperawatan sedangkan pengambilan sampel dengan menggunakan total sampling dari 3 populasi terjangkau yang dipilih berdasarkan claster pada tiga puskesmas rawat inap yakni PKM Enemawira, PKM Kuma dan PKM manganitu sebanyak 60 orang. Hasil Penelitian ini menunjukkan bahwa 48,3\% perawat yang berkinerja baik dan 51,7 \% perawat memiliki kinerja kurang. Pada penelitian ini juga didapatkan bahwa tidak terdapat hubungan yang signifikan antara pendidikan terakhir, status kepegawaian, dan lama bekerja dengan kinerja perawat dalam melaksanakan asuhan keperawatan. Diharapkan penelitian ini bisa menjadi bahan evaluasi bagi organisasi profesi perawat agar memberikan pembimbingan dan penyegaran keilmuan kepada para perawat yang kerja di puskesmas, juga penelitian ini menjadi acuan dalam pembelajaran mempersiapkan mahasiswa untuk bekerja di puskesmas di masa yang akan datang.
\end{abstract}

Kata kunci: Pendidikan, Status Kepegawaian, Lama kerja, Kinerja Askep

\begin{abstract}
Nursing services are one of the spearheads of very important health services in the community, these services focus on the application of quality nursing care which can be achieved if provided by professional nurses who are highly motivated and high-performance. This ability can be influenced by various factors comes from the nurses themselves and external factors, therefore the management must be able to identify the factors so that it can provide solutions in order to achieve the application of quality nursing care. This study aimed to know the relationship between respondent characteristics and nurse performance in implementing nursing care at the inpatient health center Sangihe Island district. The method used was cross sectional to see the relationship between education, employment status and length of work with nurses' performance in carrying out nursing care while sampling used was the total sampling of 3 affordable populations selected based on clusters at three inpatient health centers namely PKM Enemawira, PKM Kuma and PKM manganitu as many as 60 people. The results of this study indicated that $48.3 \%$ of nurses were performing well and $51.7 \%$ of nurses have poor performance. In this study also found that there was no significant relationship between recent education, employment status, and length of work with the performance of nurses in implementing nursing care. Hopely this research can be an evaluation material for professional nurses organizations to provide scientific guidance and as the refreshment for the nurses who are working at the Puskesmas, also this research become a reference for preparing students to work at the puskesmas in the future.
\end{abstract}

Keyword : Education, Employment Status, Length of Work, Nursing Care Performance. 


\section{PENDAHULUAN}

Badan Perlindungan Konsumen Nasional (BPKN) telah melakukan survei kondisi Pusat Kesehatan Masyarakat (Puskesmas) di Indonesia. Hasilnya pelayanan Puskesmas di Indonesia khususnya Puskesmas di daerah masih jauh dari harapan para pasien. Minimnya pelayanan kesehatan di Puskesmas seperti waktu tunggu yang lama, antrean yang terlalu panjang, kapasitas dokter dan sarana prasarana kesehatan dinilai masih cukup minim. BPKN melakukan riset di 15 Puskesmas di 15 KabupatenVKota di Indonesia. ungkap Anggota Komisi III BPKN Husna Zahir saat berdiskusi dengan media di Kantor Kementerian Perdagangan Jalan Ridwan Rais Jakarta Pusat, Rabu (11V12V2013) (Detik News, 2013)

Pelayanan keperawatan kesehatan pada rumah sakit atau puskesmas merupakan salah satu pelayanan yang sangat penting dan berorientasi pada tujuan yang berfokus pada penerapan asuhan keperawatan yang berkualitas, sehingga dapat memberikan suatu pelayanan kepada pasien yang menggunakan jasa. Kemampuan memberikan pelayanan asuhan keperawatan secara profesional sesuai standar keperawatan sangat tergantung pada bagaimana kinerja perawat di rumah sakit atau puskesmas dalam menerapkan standar asuhan keperawatan (Bahri, Bethan, \& Haskas, 2013).

Mutu asuhan keperawatan sangat dipengaruhi oleh kualitas pelayanan kesehatan dan bahkan sering menjadi salah satu faktor penentu citra institusi pelayanan di mata masyarakat. Untuk menjamin mutu ini, pada tahun 2005 PPNI mengeluarkan Standar Praktik Keperawatan Indonesia. Standar praktik tersebut yaitu standar praktik profesional dan standar praktik kinerja profesional.

Dengan disahkannya undang-undang keperawatan No. 38 tahun 2014 semakin memberikan pengakuan terhadap profesionalisme perawat dalam memberikan pelayanan ke pasien yakni dalam bentuk penerapan Asuhan Keperawatan, namun pada kenyataannya dilapangan sangat jarang perawat melaksanakan hal tersebut, bahkan perawat lebih percaya diri dalam melaksanakan tindakan invasif yang notabene bukan merupakan kompetensinya.

Keberhasilan perusahaan atau organisasi sangat ditentukan oleh kualitas sumber daya manusia (SDM) yang ada didalamnya. Seiring dengan persaingan yang semakin kompetitif sebagai akibat dari perubahan selera pelanggan dan teknologi, setiap perusahaan atau organisasi membutuhkan SDM yang memiliki kompetensi dan kinerja yang superior (Ola, Abdullah, Azis, 2019).

Menurut Aulia \& Sasmita (2014), Untuk meningkatkan Kompetensi dan Kinerja dan lebih khusus peningkatan pelayanan keperawatan, dapat diupayakan dengan peningkatan pengetahuan melalui pendidikan keperawatan berkelanjutan dan peningkatan keterampilan keperawatan. Pendidikan dan pelatihan mempunyai pengaruh dan signifikan terhadap kinerja perawat rawat inap.

Daerah Kabupaten Kepulauan Sangihe secara geografis merupakan daerah kepulauan yang cukup jauh dari Ibukota dan beberapa puskesmas berada di remote area, sehingga pengembangan keterampilan seperti pelatihanpelatihan sangat jarang diikuti, demikian halnya dengan pendidikan berkelanjutan. Perawat yang akan melanjutkan studinya harus meninggalkan tugasnya dan melanjutkan sudi di luar daerah.

Namun kemampuan perawat sangat diperlukan dalam mendukung tujuan yang hendak dicapai dari pelaksanaan perawatan kesehatan masyarakat. Kemampuan ini ditunjukkan dari kompetensi yang dimiliki perawat dalam 
memberikan pelayanan kesehatan kepada masyarakat.

Perawat yang ada di Puskesmas memiliki tugas tambahan yang menyita waktu kerja dan tugas pokoknya sebagai perawat, seperti di apotik, administrasi, bendahara, imunisasi dan pemegang program sehingga pemberian asuhan keperawatan belum bisa diberikan secara optimal. Penelitian mengenai kinerja perawat puskesmas sangat diperlukan hal ini bertujuan untuk mengetahui sejauh mana perawat melaksanakan tugasnya dalam memberikan pelayanan kesehatan kepada pasien di Puskesmas Rawat Inap di Kabupaten Kepulauan Sangihe

\section{METODE PENELITIAN}

Metode yang digunakan dalam penelitian ini yakni deskriptif dengan pendekatan cross sectional, Variabel dependen dalam penelitian ini ialah kinerja perawat dalam melaksanakan asuhan Keperawatan sedangkan yang menjadi variabel independen ialah tingkat pendidikan, status kepegawaian dan lama kerja, penelitian dilaksanakan pada bulan 15 Juli - 17 Agustus 2019.

Populasi target dalam penelitian ini yakni puskesmas rawat ini sebanyak 11 puskesmas dari 17 puskesmas yang ada diwilayah Kabupaten Kepulauan Sangihe sedangkan populasi terjangkau diambil berdasarkan Cluster yang mewakili tiga wilayah yakni bagian utara diambil Puskesmas Enemawira, Bagian tengah yaitu Puskesmas Kuma sedangkan bagian selatan diambil Puskesmas Manganitu.

Teknik pengambilan sampel yakni Total Sampling yaitu seluruh perawat yang melaksanakan asuhan keperawatan di ruang rawat inap di 3 puskesmas yang berjumlah 60 orang.

Pengumpulan data menggunakan kuesioner dengan metode $360^{\circ}$ yaitu melakukan penilaian dari dua sisi yakni penilaian persepsi perawat kepada dirinya sendiri dan penilaian oleh teman sejawat nilai yang diambil merupakan rerata dari penilaian tersebut sedangkan Instrumen yang digunakan di adopsi dari Instrumen penilaian kinerja perawat berdasarkan standar praktik keperawatan profesional tahun 2005.

Analisa data statistik dilakukan dengan menggunakan program komputer meliputi analisis deskriptif frekwensi untuk data univariat yakni karakteristik responden dan pada analisis bivariat yakni hubungan antara variabel independen dan dependen menggunakan uji chi squere bila memenuhi syarat dan sebagai alternatifnya menggunakan uji fisher's exact (tabel 2x2)

Penelitian ini telah mendapatkan izin penelitian dari pemerintah Daerah Kab. Kep. Sangihe melalui kepala-kepala Puskesmas yang menjadi tempat penelitian antara lain PKM Manganitu dengan No. 441/189/VIII/2019, PKM Kuma : No. 414/PKM/VIII/2019 dan PKM Enemawira dengan No. 440/PKM/VIII/2019, disamping itu pula penulis telah menjunjung tinggi dan melaksanakan prinsip etik penelitian meliputi Informed consent, Confidentiality dan Justice.

\section{HASIL DAN PEMBAHASAN}

\section{A. Hasil Penelitian}

Berikut ini akan dijabarkan hasil penelitian yang telah dilaksanakan pada bulan 15 Juli s/d 17 Agustus 2019 disajikan dalam bentuk tabel dan teks yang didasarkan pada analisis statistik. 


\section{Karakteristik Responden}

Tabel. 1 Distribusi Frekuensi Karakteristik Responden $(n: 60)$

\begin{tabular}{clcc}
\hline No & Karakteristik Responden & n & \% \\
\hline 1. & Tempat kerja responden & & \\
a. & Puskesmas Manganitu & 20 & 33,3 \\
b. & Puskesmas Kuma & 20 & 33,3 \\
c. & Puskesmas Enemawira & 20 & 33,3 \\
2. & Umur & & \\
a. & $<30$ tahun & 16 & 26,7 \\
b. & 30 s/d 40 tahun & 37 & 61,7 \\
c. & $>40$ tahun & 7 & 11,7 \\
3. & Pendidikan Terakhir & & \\
a. & Vokasional & 54 & 90,0 \\
b. & Profesional & 6 & 10,0 \\
4. & Masa Kerja & & \\
a. & $<5$ tahun & 16 & 26,7 \\
b. & 5-10 tahun & 21 & 35,0 \\
c. & $>10$ tahun & 23 & 38,3 \\
5. & Status Pekerjaan & & \\
a. & PNS & 38 & 63,3 \\
b. & Non PNS & 22 & 36,7 \\
6. & Penghasilan Perbulan & & \\
a. & $<1$ juta & 22 & 36,7 \\
b. & 1-3 juta & 9 & 15,0 \\
c. & $>3$ juta & 29 & 48,3 \\
\hline
\end{tabular}

Sumber : Data Primer 2019

Tabel 1. menunjukan responden dalam penelitian ini berjumlah 60 orang yang tersebar secara merata pada tiga puskesmas yakni Manganitu, Kuma dan Enemawira dengan usia terbanyak pada rentang 30 - 40 tahun berjumlah 37 orang $(61,7 \%)$, sementara pendidikan responden $90 \%$ ialah vokasional dan hanya $10 \%$ saja atau berjumlah 6 orang yang berpendidikan profesional (ners).

Masa kerja responden terbanyak ialah $>10$ tahun yakni 23 orang $(38,3 \%)$ dan sebagian besar berstatus sebagai Pegawai Negeri Sipil dengan jumlah 38 orang $(63,3 \%)$, sementara penghasilan terbanyak lebih dari 3 juta dengan persentasi 48,3 $\%$ atau sebanyak 29 orang.

\section{Kinerja Perawat dalam pelaksanaan asuhan} keperawatan

Kinerja perawat dalam pelaksanaan asuhan keperawatan ditunjukan dalam tabel berikut ini:

Tabel. 2 Distribusi Frekuensi Kinerja Perawat Dalam Pelaksanaan Asuhan Keperawatan di Puskesmas Rawat Inap Kab. Kep. Sangihe ( $n$ : 60)

\begin{tabular}{ccc}
\hline Kinerja Perawat & Frekuensi & $\begin{array}{c}\text { Persentase } \\
(\%)\end{array}$ \\
\hline Baik & 29 & 48,3 \\
Kurang & 31 & 51,7 \\
\hline Jumlah & 60 & 100 \\
\hline
\end{tabular}

Sumber : Data primer 2019 
Tabel 2 menunjukkan bahwa terdapat 29 orang (48,3\%) perawat yang berkinerja baik sementara sebagian besar memiliki kinerja kurang yakni sebanyak 31 orang $(51,7 \%)$.

\section{Hubungan antara pendidikan terakhir dengan kinerja}

Tabel. 3 Hubungan Pendidikan Terakhir Dengan Kinerja Perawat Dalam Melaksanakan Asuhan Keperawatan $(n: 60)$

\begin{tabular}{|c|c|c|c|c|c|c|}
\hline \multirow{3}{*}{ Pendidikan terakhir } & \multicolumn{4}{|c|}{ Kinerja } & \multirow{3}{*}{ Total } & \multirow{3}{*}{$p$} \\
\hline & \multicolumn{2}{|c|}{ Baik } & \multicolumn{2}{|c|}{ Kurang } & & \\
\hline & $\mathbf{n}$ & $\%$ & $\mathbf{n}$ & $\%$ & & \\
\hline Vokasional & 25 & 46,3 & 29 & 53,7 & 52 & \\
\hline Profesional & 4 & 66,7 & 6 & 33,3 & 8 & 0,417 \\
\hline
\end{tabular}

Tabel. 3 menyajikan responden yang berpendidikan ners sebagian besar memiliki kinerja baik yakni sebanyak 66,7 \% (4 orang) sedangkan pada responden dengan pendidikan vokasional sebagian besar memiliki kinerja kurang yakni sebanyak 53,7 \% (29 orang), hasil analisis uji fisher exact diperoleh nilai $p$ value $0,417(p>0,05)$ artinya tidak terdapat hubungan yang signifikan antara pendidikan terakhir dengan kinerja perawat dalam melaksanakan asuhan kperawatan.

\section{Hubungan antara status kepegawaian dengan kinerja}

Tabel. 4 Hubungan Antara Status Kepegawaian Dengan Kinerja Perawat Dalam Melaksanakan Asuhan

\begin{tabular}{|c|c|c|c|c|c|c|}
\hline \multirow{4}{*}{ Status kepegawaian } & \multicolumn{6}{|c|}{ Keperawatan $(n: 60)$} \\
\hline & \multicolumn{4}{|c|}{ Kinerja } & \multirow{3}{*}{ Total } & \multirow{3}{*}{$p$} \\
\hline & \multicolumn{2}{|c|}{ Baik } & \multicolumn{2}{|c|}{ Kurang } & & \\
\hline & $\mathbf{n}$ & $\%$ & $\mathbf{N}$ & $\%$ & & \\
\hline PNS & 18 & 47,4 & 20 & 52,6 & 38 & \\
\hline Non PNS & 11 & 50,0 & 11 & 50,0 & 22 & 1,00 \\
\hline
\end{tabular}

Analitik statistik chi square $\alpha=0,05$ (expected counted $0 \%$ )

Tabel. 4 menyajikan informasi bahwa terdapat 18 responden $(47,4 \%)$ yang berstatus sebagai PNS dan memiliki kinerja baik sementara PNS yang berkinerja kurang lebih besar yakni sebanyak 20 orang (52,6 $\%$ ), sedangkan responden yang berstatus sebagai non PNS memiliki kinerja yang sama yakni $50 \%$ (11 orang) berkinerja baik dan $50 \%$ lainnya berkinerja kurang. Hasil uji chi square diperoleh nilai $p$ value 1,00 $(p>0,05)$ dengan demikian tidak terdapat hubungan yang signifikan antara status kepegawaian dengan kinerja perawat dalam melaksanakan asuhan keperawatan. 


\section{Hubungan antara lama kerja dengan kinerja}

Tabel. 5 Hubungan Antara Lama Kerja Dengan Kinerja Perawat Dalam Melaksanakan Asuhan Keperawatan

\begin{tabular}{|c|c|c|c|c|c|c|}
\hline \multirow{3}{*}{ Lama kerja } & \multicolumn{4}{|c|}{ Kinerja } & \multirow{3}{*}{ Total } & \multirow{3}{*}{$p$} \\
\hline & \multicolumn{2}{|c|}{ Baik } & \multicolumn{2}{|c|}{ Kurang } & & \\
\hline & $\mathbf{n}$ & $\%$ & $\mathbf{n}$ & $\%$ & & \\
\hline$<5$ tahun & 10 & 62,5 & 6 & 37,5 & 16 & 0416 \\
\hline 5-10 tahun & 9 & 42,9 & 12 & 57,1 & 21 & 0,410 \\
\hline$>10$ tahun & 10 & 43,5 & 13 & 56,5 & 23 & \\
\hline
\end{tabular}

Tabel. 5 menyajikan informasi bahwa pada responden dengan lama kerja $<5$ tahun sebagian besar memiliki kinerja baik yakni sebanyak 62,5 \% (10 orang) sedangkan responden dengan lama kerja 5-10 tahun maupun dengan lama kerja > 10 tahun dominan memiliki kinerja kurang yakni 57,1\% (12 orang dan 56,5\% (13 orang). Sedangkan pada uji chi square diperoleh nilai $p$ value $0,416(p>0,05)$ dengan demikian tidak terdapat hubungan yang signifikan antara lama kerja dengan kinerja perawat dalam melaksanakan asuhan keperawatan.

\section{B. Pembahasan}

Pada bagian ini akan diuraikan tentang hasil penelitian yang meliputi interpretasi dan diskusi berdasarkan literatur serta kesesuaian antara hasil penelitian lainnya yang dijabarkan berdasarkan hubungan antara setiap variabel

\section{Hubungan pendidikan terakhir dengan kinerja perawat}

Hasil penelitian menunjukkan perawat profesional dengan pendidikan ners sebagian besar memiliki kinerja baik, hal sebaliknya dengan perawat vokasional dengan pendidikan diploma dimana sebagian besar memiliki kinerja kurang, walaupun pada uji bivariat dengan fisher's exact tidak bermakna namun data tersebut cukup memberikan arti bahwa semakin tinggi tingkat pendidikan makan akan berbanding lurus dengan kinerja yang diperlihatkan.

Hasil penelitian ini sejalan dengan penelitian yang dilakukan oleh Hartati (2013) tentang gambaran kinerja perawat dalam melaksanakan asuhan keperawatan di Instalasi Rawat Inap Lontara RSUP Dr. Wahidin Sudirohusoda Makassar dimana pada perawat dengan pendidikan ners memiliki kinerja yang lebih baik dibandingkan dengan perawat vokasi.

Hal senada juga yang didapatkan oleh Pramitasari (2016) dalam penelitiannya tentang kinerja perawat dalam pendokumentasian Asuhan Keperawatan berbasis komputer di RS Banyumas didapatkan perawat yang berpendidikan SI maupun Ners memiliki kinerja lebih baik dibanding dengan perawat diploma. 
Penelitian yang dilakukan oleh Yoo \& Kim (2017) di Rumah Sakit tipe C di Korea mengenai kegiatan yang meningkatkan kualitas pelayanan keperawatan menunjukkan bahwa ada hubungan antara Pendidikan dengan kualitas pelayanan. Demikian halnya dengan penelitian yang dilaksanakan oleh Saleh, Ali, \& Afifi (2018) di ElMenia University Hospital, Egypt pada 41 perawat menunjukkan bahwa pendidikan dan pelatihan sangat efektif dalam meningkatkan pengetahuan dan keterampilan perawat.

Pendidikan merupakan proses pembelajaran yang dilakukan seseorang untuk mendapatkan pengetahuan, sehingga semakin tinggi pendidikan seseorang pasti akan berbanding lurus dengan pengetahuan yang dimilikinya, perawat dengan profesi ners akan memiliki pengetahuan yang sangat memadai tentang pelaksanaan asuhan keperawatan sehingga dalam penerapannya dilapangan akan lebih komprehensif (Notoatmodjo, 2007)

Berdasarkan pengamatan penulis dilapangan terlihat perawat dengan pendidikan diploma cenderung melakukan tindakan keperawatan saja, namun pendokumentasian secara menyeluruh terhadap proses keperawatan mulai dari pengkajian sampai dengan evaluasi masih belum terlaksana dengan baik, hal yang tak dapat dipungkiri berdasarkan standar profesi terhadap kewenangan seorang perawat bahwa perawat dengan pendidikan ners yang memiliki kewajiban secara komprehensif dalam pelaksanaan asuhan keperawatan terutama dalam aspek pengkajian, diagnosa dan perencanaan (PPNI, 2005).

\section{Hubungan status kepegawaian Dengan Kinerja}

Hasil penelitian menunjukan tidak terdapat hubungan yang bermakna antara status kepegawaian dengan kinerja perawat dalam melaksanakan asuhan keperawatan, hal tersebut sejalan dengan penelitian yang dilakukan oleh Syaifullah (2013) dengan judul pengaruh status kepegawaian terhadap kinerja perawat di ruang rawat inap RSUD Kabupaten Indramayu dimana ditemukan kinerja yang sama antara perawat yang berstatus sebagai PNS dan Non PNS.

Status pekerjaan akan berkaitan erat dengan kompensasi yang diberikan, seorang dengan status PNS tentunya akan memiliki penghasilan yang lebih besar dibanding Non PNS, akan tetapi dari faktor tersebut tidak menjadi suatu hal pasti dapat berpengaruh terhadap kinerja, Penelitian yang telah dilakukan oleh Gobel (2014) tentang hubungan antara system reward dengan kinerja perawat dalam melaksanakan askep ditemukan reward ektrinsik dalam bentuk insentif tidak memiliki hubungan sedangkan reward intrinsik dalam bentuk non insentif justru memiliki hubungan yang erat dengan kinerja. 
Hasil yang berbeda didapatkan dalam penelitian Nugraha (2017) dengan judul pengaruh status pekerja dan lingkungan kerja terhadap kinerja karyawan ditemukan hasil yakni kinerja karyawan tetap lebih baik daripada kinerja karyawan tidak tetap, hal tersebut mengindikasikan bahwa kinerja bersifat sangat subjektif dan dapat dipengaruhi oleh faktor lainnya secara bersamaan dalam satu lingkungan kerja.

Hasil analisis penulis dilapangan perawat Non PNS yang bekerja ditiga Puskesmas mereka memiliki komitmen yang tinggi terhadap pekerjaannya, karena sebagaian besar dari mereka ialah orang asli daerah atau berada diseputara Puskesmas tersebut dan merupakan perawat yang baru menyelesaikan studinya dan telah lulus dalam uji kompetensi sehingga hal itulah yang menjadi motivasi bagi mereka dalam melaksanakan asuhan keperawatan.

3. Hubungan lama kerja dengan kinerja perawat

Lama kerja merupakan salah satu faktor yang dapat mempengaruhi kinerja seseorang, semakin lama seseorang itu bekerja maka akan semakin berpengalaman dalam pekerjaannya sehingga akan memberikan kinerja yang lebih baik (Robins, 2005)

Penelitian yang dilakukan oleh Putri (2019) dimana menjelaskan semakin lama orang bekerja maka pengalaman serta pemahaman terhadap pekerjaannya akan lebih baik dan akan terbentuk komitmen yang tinggi dan dengan komitmen tersebut akan membuat seseorang lebih bertanggungjawab atas pekerjaannya (Putri, 2019)

Hasil penelitian memberikan makna yang berbeda dimana walaupun secara statistik ditemukan nilai $p$ value $0,416(p>0,05)$ namun secara deskriptif pada tabel distribusi frekwensi terlihat perawat dengan masa kerja $<5$ tahun sebagaian besar menunjukan kinerja lebih baik disbanding perawat dengan masa kerja diatasnya, hal tersebut memberikan makna tidak selamanya perawat yang berpengalaman lebih dengan masa kerja lama akan memberikan kinerja lebih baik.

Menurut Robins (2005) lama kerja turut menentukan kinerja seseorang dalam menjalankan tugas, akan tetapi bila ditindaklanjuti oleh kebijakan organisasi yang baik, faktor tidak adanya hubungan antara masa kerja bisa saja terjadi disebabkan karena adanya kejenuhan terhadap rutinitas pekerjaan dan kebiasaan pendokumentasian, selain itu kurangnya pembinaan mengenai pendokumentasian asuhan keperawatan terhadap para perawat pelaksana sehingga motivasi untuk mendokumentasikan asuhan keperawatan rendah.

Penelitian yang dilakukan oleh Shanty, Rantetampang, \& Mallongi (2019)di Rumah Sakit Umum Jayapura pada 111perawat menunjukkan bahwa pengalaman kerja tidak berpengaruh 
terhadap pemberian asuhan keperawatan, hal lainnya yang tidak berpengaruh yaitu usia, jenis kelamin, pendidikan, pengalaman kerja, pelatihan, dan kenyamanan terhadap tempat bekerja.Faktor yang mempengaruhi kinerja perawat dalam memberikan asuhan keperawatan adalah motivasi, sikap, dan supervisi.

Bertambahnya lama kerja seorang perawat sebaiknya disertai dengan kegiatan untuk meningkatkan keterampilan, pengetahuan, dan kemampuan setiap individu agar tidak terjadi kejenuhan terhadap rutinitas sehingga kualitas dokumentasi menjadi lebih baik.

\section{KESIMPULAN}

Hasil Penelitian ini menunjukkan bahwa dalam penerapan asuhan keperawatan di ruang rawat inap 48,3 \%perawat memiliki kinerja yang baik dan 51,7 \% perawat memiliki kinerja kurang. Pada penelitian ini juga didapatkan bahwa tidak terdapat hubungan yang signifikan antara pendidikan terakhir, status kepegawaian, dan lama bekerja dengan kinerja perawat dalam melaksanakan asuhan keperawatan. Sedangkan saran yang diberikan Bagi Dinas Kesehatan yakni dapat melakukan evaluasi dan pengawasan serta penyegaran keilmuan terhadap para perawat dan Bagi Puskesmas diharapkan dapat mengikutsertakan para perawat saat pelatihan pengembangan keilmuan, dan menggunakan sistem informasi digital untuk mendukung pelaksanaan tugas perawat.

a. Bagi Organisasi Profesi : PPNI kiranya dapat memfasilitasi penyusunan format asuhan keperawatan yang seragam yang bisa digunakan oleh perawat di tiap puskesmas. b. Bagi Peneliti selanjutnya : Peneliti selanjutnya bisa melaksanakan / mengembangkan suatu standar askep di puskesmas.

\section{DAFTAR RUJUKAN}

Detik News. (2013). Kondisi Puskesmas di Indoneisa. Diambil dari https://news.detik.com/berita/2438995/in i-kondisi-puskesmas-di-indonesiaantrean-panjang-dan-dokter-yang-kurang

Depkes RI. (2007). Pedoman Pengobatan Dasar di Puskesmas. Diambil dari http://www.pkfi.net/file/download/Pedo man\%20Pengobatan\%20Dasar\%20di\%2 0Puskesmas\%202007.pdf

Hartati., Noer B. N\& Maidin A. (2013). Gambaran Kinerja Perawat Dalam Pelaksanaan Asuhan Keperawatan Di Instalasi Rawat Inap Lontara RSUP Dr.Wahidin Sudirohusodo diakses tanggal 20/3/20 URL $<$ http://repository.unhas.ac.id/handl e/123456789/8621>

Permenkes No 18 Tahun 2017. Penyelenggaraan Uji Kompetensi Jabatan Fungsional Kesehatan.

Potter, Perry. (2010). Fundamental of Nursing Concept, Proces, and Practice. Edisi 7. Vol.3. Jakarta: EGC

Menkes No. 75 Tahun 2014. Pusat Kesehatan Masyarakat.

Notoatmodjo S. (2007). Promosi Kesehatan \& Ilmu Perilaku. Rineke Cipta. Jakarta

Nugraha B. A., Soe'oed M., Susilo H. H. (2017). Pengaruh Status Pekerja Dan Lingkungan Kerja Terhadap Kinerja Karyawan (Studi Pada Karyawan Auto 2000 Sukun Malang). Jurnal Administrasi Bisnis (JAB)|Vol. 44 No.1 Maret 2017|

PPNI (2005). Standar Kompetensi Perawat Indonesia. DiPublikasi Oleh Bidang Organisasi PP-PPNI melalui; http://www.inna-ppni.or.id 
Pramithasari, I. D. (2016). Gambaran Kinerja Perawat Dalam Mendokumentasikan Asuhan Keperawatan Berbasis Komputer Di RSUD Banyumas. Jurnal Keperawatan Muhammadiyah, 1 (1): 4045 .

Putri., Irianto W. S. (2019) Pengaruh Komitmen, Organizational Citizenship Behavior (Ocb), Motivasi Dan Kemampuan Terhadap Kinerja Perawat Pada Rumah Sakit Umum Daerah Jombang Thesis, Universitas Pesantren Tinggi Darul 'Ulum. Diakses pada 20 maret 2020. URL

<http://Eprints.Unipdu.Ac.Id/1650/>

Retyaningsih I. Y., Bambang E. W. (2013). Hubungan Karakteristik Perawat, Motivasi, Dan Supervisi Dengan Kualitas Dokumentasi Proses Asuhan Keperawatan Jurusan Keperawatan, Fakultas Kedokteran, Universitas Diponegoro. Jurnal Managemen Keperawatan . Volume 1, No. 2, November 2013; 107-114

Robins, S., Coulter M (2005). Manajemen. Edisi Delapan. Jilid I. Jakarta. IndeksSaefulloh M. (2013). Pengaruh Status Kepegawaian Terhadap Kinerja Perawat Di Ruang Rawat Inap. Jurnal Kebidanan Dan Keperawatan Vol. 9 No. 1, Juni

\section{ISSN 1858-0610}

Saleh, M., Ali, J., \& Afifi, W. (2018). Nurses Compliance to Standards of Nursing Care for Hemodialysis Patients: Educational and Training Intervention. IOSR Journal of Nursing and Health Science (IOSR-JNHS) e-ISSN, 2320$1959 . \quad$ Diambil dari https://pdfs.semanticscholar.org/799c/f1 c4fcfc1c3c278654ebdb2a38ac9744bb9f. pdf

Shanty, Y. M., Rantetampang, A. L., \& Mallongi, A. (2019). The factors affecting performance of nurse in heath care giver at internal room hospital public Jayapura. Diambil dari http://www.cldcollege.com/download/IJ SHR.pdf\#page $=29$

Standar Praktik Keperawatan Indonesia. (2005). PPNI : Jakarta

Sualman, Kamisa. (2009). Public Health Nursing. Riau : Faculty of Medicine University of Riau. Diambil dari http://www.Bclibis17.tk

Yoo, J. Y., \& Kim, K. J. (2017). A Study on the Quality Improvement Activities of Clinical Nurses: Nursing Care Unit level. Korea Journal of Hospital Management, 22(1), 10-20. Diambil dari http://www.koreascience.or.kr/article/JA KO201714940711417.pag 